\title{
Some memories of Cy Derman
}

\author{
Alvin E. Roth
}

Published online: 24 July 2013

(C) The Author(s) 2013. This article is published with open access at Springerlink.com

I came to Columbia in 1968 as an undergraduate in the engineering school. I didn't know what I wanted to major in, and declared an interest in nuclear engineering, so that I could take as many physics courses as I wanted. But the summer after my freshman year I took a summer job in Washington D.C. at an Army lab for which I had qualified by taking a civil service exam. They had an OR group, and I returned to school as an OR major.

In the manner of undergraduates, I didn't have a clear idea of what my teachers did. But I recall admiring Cy Derman's attitude: he seemed not to take himself too seriously. I recall he wore turtleneck shirts and talked about tennis, and summers at Stanford.

When it came time to think about graduation, Cy urged me to think about grad school in $\mathrm{OR}$, and volunteered to write a letter for me. Some time later, in a reflective moment, he said something to me like "I wrote you a very good letter. I'm not exactly sure why; you didn't do all that well in your courses. But I have a feeling that you might be good at research." Cornell and Stanford were the programs he recommended, and when I was accepted at both, his preference was clear, and I followed his advice, which set me on a path I'm still following.

A.E. Roth ( $\varangle)$

Department of Economics, Stanford University, Stanford, CA 94025, USA

e-mail: alroth@stanford.edu 